\title{
Modelling Nuclear Morphology and Shape Transformation: A Review
}

\author{
Chao Fang ${ }^{1,2}$, Jiaxing Yao ${ }^{1,2}$, Xingyu Xia ${ }^{1,2}$ and Yuan Lin $1,2,3, * \mathbb{D}$ \\ 1 Department of Mechanical Engineering, The University of Hong Kong, Hong Kong, China; \\ chfong@connect.hku.hk (C.F.); yaojx@connect.hku.hk (J.Y.); u3005822@connect.hku.hk (X.X.) \\ 2 HKU-Shenzhen Institute of Research and Innovation (HKU-SIRI), Shenzhen 518057, China \\ 3 Advanced Biomedical Instrumentation Centre, Hong Kong Science Park, Shatin, New Territories, \\ Hong Kong, China \\ * Correspondence: ylin@hku.hk
}

Citation: Fang, C.; Yao, J.; Xia, X.;

Lin, Y. Modelling Nuclear

Morphology and Shape

Transformation: A Review.

Membranes 2021, 11, 540.

https://doi.org/10.3390/

membranes 11070540

Academic Editor: Terry Hébert

Received: 17 June 2021

Accepted: 14 July 2021

Published: 16 July 2021

Publisher's Note: MDPI stays neutral with regard to jurisdictional claims in published maps and institutional affiliations.

Copyright: (c) 2021 by the authors. Licensee MDPI, Basel, Switzerland. This article is an open access article distributed under the terms and conditions of the Creative Commons Attribution (CC BY) license (https:/ / creativecommons.org/licenses/by/ $4.0 /)$.

\begin{abstract}
As one of the most important cellular compartments, the nucleus contains genetic materials and separates them from the cytoplasm with the nuclear envelope (NE), a thin membrane that is susceptible to deformations caused by intracellular forces. Interestingly, accumulating evidence has also indicated that the morphology change of NE is tightly related to nuclear mechanotransduction and the pathogenesis of diseases such as cancer and Hutchinson-Gilford Progeria Syndrome. Theoretically, with the help of well-designed experiments, significant progress has been made in understanding the physical mechanisms behind nuclear shape transformation in different cellular processes as well as its biological implications. Here, we review different continuum-level (i.e., energy minimization, boundary integral and finite element-based) approaches that have been developed to predict the morphology and shape change of the cell nucleus. Essential gradients, relative advantages and limitations of each model will be discussed in detail, with the hope of sparking a greater research interest in this important topic in the future.
\end{abstract}

Keywords: nuclear mechanics; shape transformation; continuum models

\section{Introduction}

As one of the most important cellular components, the nucleus is widely believed to play critical roles in processes such as mitosis [1-3], cell spreading [4-7] and migration [8-12]. For instance, the nuclear membrane in most eukaryotic cells will be dissolved during mitosis and then get reassembled in daughter cells $[13,14]$ while it will remain largely intact in fission yeasts, i.e., only local disassembly of the nuclear envelope (NE) occurs at the end of mitosis to accomplish daughter nuclei separation [15]. The role of the nucleus as a mechanosensor for environmental stimuli [16-19], a transducer for downstream signaling [20-24] and a ruler for active cellular responses $[10,11,25,26]$ has also been well-documented. Taking cell migration as an example, severe distortion could take place when the cell passes through tight spaces or moves in blood vessels. In plant cells, turgor pressure in the vacuole will also deform other organelles $[27,28]$. Such deformations can be transduced to the nucleus, lead to its morphology changes and eventually trigger corresponding cell reactions. Finally, the nucleus has been examined as a potential marker for diseases like cancer $[22,29,30]$ and laminopathies, including Hutchinson-Gilford Progeria Syndrome [22,31-36] and Emery-Dreifuss muscular dystrophy [37-39], where the disorder was found to arise from the absence/malfunction of gene $L M N A$ (coding lamin A/C) or STA (coding nuclear protein emerin) that leads to nuclear dysfunction and morphology abnormalities.

Various advanced techniques (such as microrheology [40,41], micropipette aspiration [42-45], microplate manipulation [46,47], atomic force microscopy (AFM) indentation [48,49], fluorescence correlation spectroscopy (FCS) [50], all-optical Brillouin microscopy [51], optical tweezer [52], laser microsurgery [53]) have been developed/adopted 
in the past two decades to monitor nuclear morphology change or characterize the physical properties of individual nuclear components. However, due to complicated interactions/connections among different nuclear constituents, it's not easy to experimentally decouple their roles in determining the shape and bulk mechanical response of the nucleus. For this reason, many theoretical models have been developed to delineate the individual and collective contributions of each nuclear constituent [54,55], as well as provide explanations to a variety of puzzling observations [56,57].

Roughly speaking, existing models capable of describing/predicting nuclear morphology transformation can be divided into two categories: continuum and molecular dynamics models. Here, we focus on continuum-level approaches while molecular dynamics simulations will not be discussed. Interested readers could refer to [58] for a review on that front. Specifically, different biophysical elements involved in regulating nuclear shape change will be discussed first before the introduction of three main types of continuum (i.e., energy minimization, boundary integral and finite element-based) models. Essential gradients, advantages and suitability (for examining different cellular processes) of each approach will be discussed in detail. In the end, we will also share our views on the future of this important field.

\section{Biophysical Elements Involved in Regulating Nuclear Morphology}

Before we plunge into the details of different models, it is important to identify major biophysical elements involved in nuclear morphology regulation. For example, both the physical characteristics of the surrounding environment and the complex intracellular/intranuclear structure were found to play key roles in the mechanotransduction and shape transformation of the cell nucleus. Therefore, the influencing biophysical factors can be approximately summarized as nuclear structure, cytoskeleton (i.e., actin filaments, intermediate filaments and microtubules), extracellular matrix (ECM), cell adhesion, spatial physical confinement and medium osmolarity.

\subsection{Internal Structure of the Nucleus}

Serving as the space for protecting genetic materials and the site for gene transcription, the cell nucleus is known for its complicated inner organization. From the structure point of view, the nucleus contains a nuclear envelope (NE), a lamina layer underneath the NE and chromatins enclosed in the center (Figure 1). The NE consists of double bilayer membranes-an inner nuclear membrane (INM) and an outer nuclear membrane (ONM) [59]. These two membranes are separated by a 30-50 nm-thick interval [23] in general but can fuse together locally to form nuclear pore complexes (NPCs) on the NE [60-62], allowing transport of small size solutes, water molecules, proteins, mRNA and macromolecular complexes between the cytoplasm and nucleoplasm to take place. Underneath the INM, a lamina layer (a complex network of intermediate filaments lamin $\mathrm{A} / \mathrm{C}, \mathrm{B} 1$ and B2), with thickness ranging 10-50 nm [63] is usually formed in mammalian cells but is absent in fission yeasts [64], making their nuclei more susceptible to forceinduced shape changes. This lamina layer binds to INM via proteins such as emerin while, at the same time, connects to the cytoskeleton through the so-called linkers of nucleoskeleton and cytoskeleton (LINC) complex (composed of the nesprin family proteins, that include Klarsicht/ANC-1/SYNE homology (KASH) domain, in ONM and Sad1/UNC84 (SUN) proteins in INM) $[23,65,66]$. On the other hand, through the lamin-associated proteins (LAP), the lamina network also establishes connections with chromatins [67] whose adjustable condensation/decompaction can then affect gene expression of the cell $[68,69]$. This "LINC-NE-lamina layer-chromatin" chain serves as a critical pathway for transmitting extranuclear signals to the nucleus and eventually allowing mechanotransduction in cells to take place. 


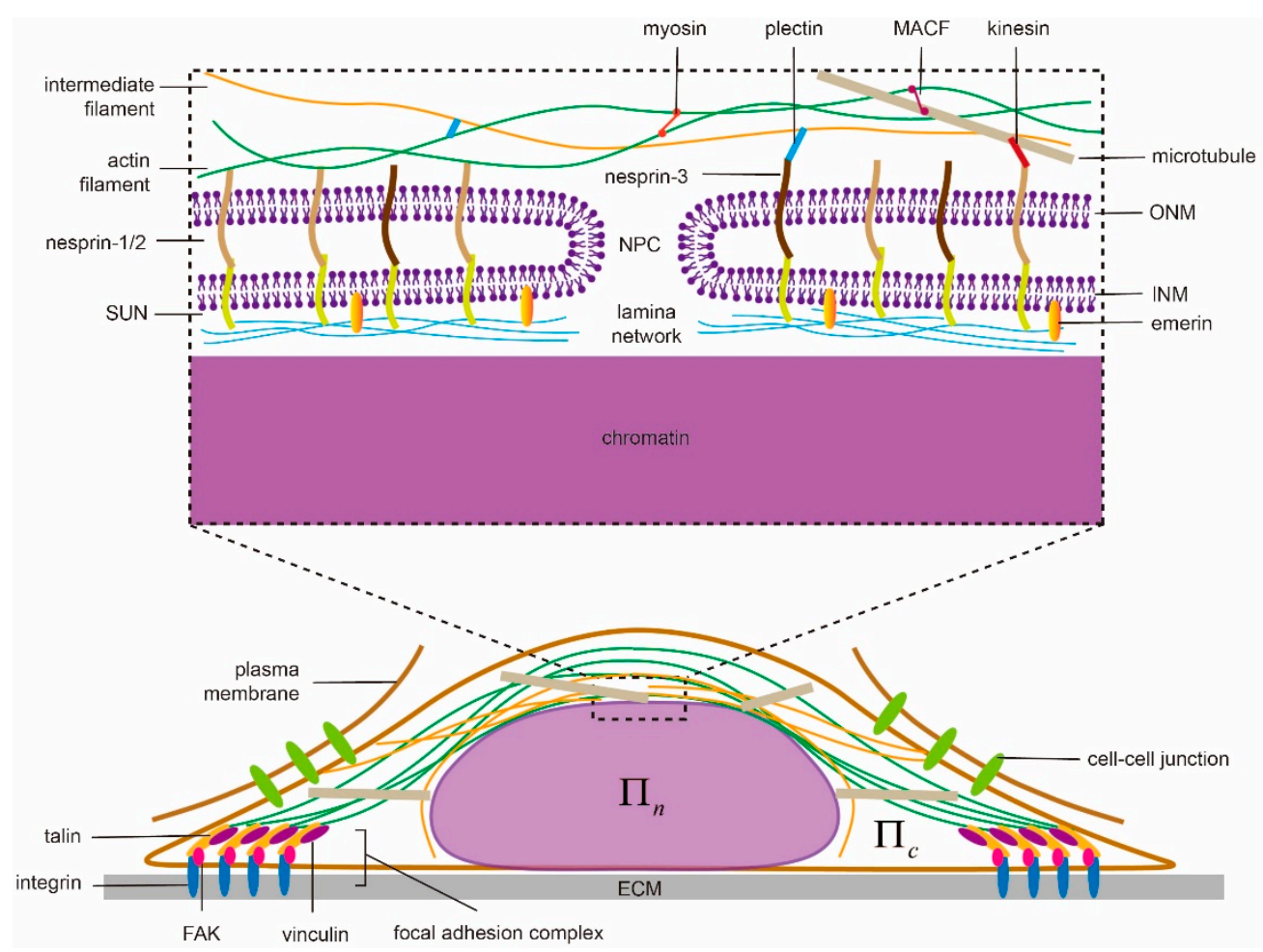

Figure 1. Illustration of biophysical elements regulating nuclear morphology and shape transformation in adherent cells, i.e., nuclear structures and connections, cytoskeleton, extracellular matrix (ECM), cell adhesions and osmolarity. ECM can modulate the nuclear shape through focal adhesions and the associated stressed cytoskeleton with patterns known as perinuclear actin cap and vimentin cage. They transduce inter/intracellular contraction generated by motor proteins to compress the nucleus whose proper functioning largely depends on the linkers of nucleoskeleton and cytoskeleton (LINC) complexes (composed of nesprin family proteins in outer nuclear membrane (ONM) and Sad1/UNC-84 (SUN) proteins in inner nuclear membrane (INM)) and active motor proteins. In addition to chromatin condensation, the integrity of the lamina network layer and its links to INM (via emerin) defines the nuclear deformation ability. Any malfunction of them could lead to abnormal nuclear morphology or failure of shape transformation. In contrast, the osmotic pressure difference between the nucleoplasm $\left(\Pi_{n}\right)$ and cytoplasm $\left(\Pi_{c}\right)$ could tune the shape by water absorption/leakage without solid contact.

\subsection{Cytoskeleton}

By transducing forces generated by motor proteins like kinesin, dynein and myosin or pushing the nuclear membrane directly via polymerization, the cytoskeleton (composed of actin filaments, intermediate filaments and microtubules) plays important roles in regulating the shape of the cell nucleus. Specifically, F-actin can connect directly to the actin-binding domain of nesprin-1/2 [70] on the nuclear membrane while the binding between microtubules and nesprin-1/2 has been suggested to be mediated by kinesin [71,72]. In contrast, cytoskeleton linker protein plectin is believed to link intermediate filaments to nesprin-3 on the ONM [73] (Figure 1). Note that the three categories of filaments are interconnected with each other via cross-linkers as well. For instance, microtubules-actin cross-linking factor (MACF) works as a joint between F-actin and microtubules [74] while plectin connects actin and intermediate filaments [75]. As such, the presence or absence of any type of these filaments could adjust the mechanical response of the cytoskeleton and eventually regulate nuclear morphology. In Drosophila, for example, polymerizing microtubules can indent the nucleus, cause its movement [76] and induce membrane grooves [77]. Interestingly, the grooves may even develop into full membrane folds [78]. In another case, when the cell is detached from the substrate, microtubules and the perinuclear actin cap can compress the nucleus and lead to buckling of the NE [79]. Note that, perinuclear actin cap is an organized doom-like stress fibers network, connecting to LINC complexes (refer to Figure 1), that has 
been observed in a wide range of adherent cells (i.e., 3T3 fibroblasts, $\mathrm{C} 2 \mathrm{C} 12$ mouse myoblasts, human endothelial cells and human ovarian epithelial cells) [7]. Such structure is believed to play critical roles in protecting the nucleus from extracellular physical disturbances [4], regulating cell migration [80] and facilitating mechanosensation/mechanotransduction [81]. For instance, during the spreading of cells, the apical actin cap will transmit cortical tension to compress the nucleus. Then the flattened nucleus will be resisted/confined by lateral stress fibers, eventually resulting in its elongation [57]. Similarly, it was found that vimentin, a type III intermediate filament protein, could form a cage-like network around the nucleus, which organizes its shape and helps it resist severe deformations by enhancing perinuclear stiffness $[82,83]$. Experimentally, the nuclei of vimentin deficient $\left(\mathrm{vim}^{-}\right)$cells exhibit a clearly rounder morphology compared to the oblate spheroidal nuclei in vim ${ }^{+}$cells [82]. On the other hand, the nuclear contour of the latter is much smoother than that in vimentin deficient cells where folding and invaginations of the nuclear membrane are often observed $[82,84]$. Physically, it is believed that the elevated tension level within the nuclear membrane, caused by the surrounding vimentin cage, could suppress its thermal fluctuations and lead to a smoother morphology [82].

\subsection{Extracellular Matrix and Cell Adhesion}

It has been well documented that the cell can form larger focal adhesions and develop higher intracellular contraction on a more rigid extracellular matrix [85,86], suggesting cells are capable of sensing the physical characteristics of their microenvironment and then reacting accordingly [86-91]. Recent evidence also indicated that the nuclear shape of cells is regulated by ECM rigidity as well. Specifically, the nucleus was found to be flattened on rigid substrates while remained tall on soft ones. Interestingly, such influence (of ECM rigidity) disappears once myosin activity is inhibited or LINC complexes in the cells are disrupted [6]. Furthermore, ECM geometry also appears to play a role in affecting the shape of the cell [92] and its nucleus [7,57]. In particular, ECMs with high aspect ratios were found to result in severely elongated nuclei along with anisotropically distributed focal adhesions [57]. It must be pointed out that these aforementioned nuclear shape changes are all mediated by cell-ECM adhesions (Figure 1) where a number of proteins, including integrin, vinculin, focal adhesion kinase (FAK), and talin, are assembled together [93]. For example, the ECM rigidity sensing capability of cells was thought to originate from the force-dependent unfolding (and subsequent vinculin binding) of talin [86]. Interestingly, recent evidence also suggested that cadherin-based cell-cell contact (Figure 1) could affect the positioning [94] and deformability [95] of the cell nucleus as well.

\subsection{Physical Confinement}

A myriad of investigations showed that, when passing through tightly confined spaces, the cell nucleus can be squeezed into an elongated or a dumbbell-like shape [8,10-12,96-98]. Furthermore, when the confinement is narrower than a threshold size, unfolding of the NE (i.e., flattening of the originally wrinkled surface) will take place, releases calcium from the nuclear membrane and activates the calcium-dependent phospholipase cPLA2, eventually enhancing the actomyosin contractility and migration capability of the cell $[10,11]$. Actually, this has been thought of as a self-protection mechanism for cells to escape tight confinements (and hence avoid possible damages induced by severe cellular deformations). Note that, unlike the NE flattening due to integrin-based adhesion or cytoskeleton compression [4], the unfolding of NE, in this case, is merely caused by physical confinements.

\subsection{Osmolarity}

In contrast to all other factors mentioned above, no physical contact is needed for osmotic pressure to regulate the shape and activity of cells [99-103]. Interestingly, although NPCs allow small-sized molecules and water to pass through the nuclear membrane, the volume and shape of the cell nucleus are still sensitive to extracellular osmolarity. For example, the nuclear volume was observed to grow linearly with the decreasing medium 
osmolarity initially but become rather insensitive to it in the deep hypo-osmotic range while the nuclear surface becomes smoother [104]. In addition, after the sudden removal of mechanical stresses exerted on the nucleus, the rapidly changed osmotic pressure was found to lead to shrinkage of the nucleus as well as buckling of the NE [79].

\section{Continuum Models for Describing Nuclear Morphology}

\subsection{Energy Minimization Model}

After the pioneering works by Canham [105] and Helfrich [106], the approach of energy minimization has been widely adopted in describing the shape change of biological membranes or fluid vesicles including the NE [107-112]. Essentially, the stable shape of NE under loading is the one that minimizes the total energy of the system. Specifically, by taking membrane bending and stretching into account, this elastic energy stored can be expressed as

$$
W=\iint_{S}\left[\frac{1}{2} K_{b}\left(C_{1}+C_{2}\right)^{2}+\frac{1}{2} K_{A}\left(\frac{A-A_{0}}{A_{0}}\right)^{2}\right] d S
$$

where $K_{b}$ refers to bending rigidity of membrane, $C_{1}$ and $C_{2}$ are the two principal curvatures. Note that the so-called spontaneous curvature of membrane and Gaussian bending energy are ignored here because the former vanishes when the lipid composition of bilayer membrane is the same and the integration of the Gaussian curvature on a closed surface is simply a constant. The second term of the integrand represents stretching energy density in which the membrane tension can be expressed as $\gamma=K_{A} \frac{A-A_{0}}{A_{0}}$, with $K_{A}, A, A_{0}$ being areal expansion modulus, real and un-stretched membrane area, respectively. Sometimes, $\gamma$ is treated as a constant (i.e., independent of membrane area $A$ ) because the ONM is continuous with the endoplasmic reticulum (ER) which works like a lipid reservoir to maintain the membrane tension level [107-109].

Taking closed mitosis of fission yeast as an example, since the volume enclosed by the NE $\left(V_{n}\right)$ remains largely as a constant [2,3] during this process a term $-P V_{n}$ needs to be added to the right hand side of Equation (1) with $P$ working as a Lagrange multiplier $[107,109]$ to enforce the volume conservation condition. In addition, given that gradual separation between its two poles is driven by growing spindle microtubules inside the nucleus during closed mitosis [1-3,53], a corresponding potential term should also be considered. For instance, by assuming that the elongating microtubule bundles effectively generate a concentrated force $f$ on both poles (Figure 2A), a term

$$
W_{m t}=-f L
$$

can be added to Equation (1) with $L$ representing the pole-to-pole distance of the NE [109].

This simple description successfully explained the formation of single or double lipid tethers after the connection between microtubule bundles and spindle pole bodies (SPBs) was destroyed by laser severing [1]. On the other hand, the fact that chromatins bind to INM via LEM (LAP2, emerin, Man1) domain proteins, i.e., Heh1, Heh2 [113,114], suggests that the spindle force could be transmitted to the NE through chromatins. Therefore, Zhu and coworkers proposed that the pushing force $f$ from growing microtubules is distributed to the NE over a load transmitting area with characteristic size $s_{\mathcal{c}}$. Effectively, a potential term of the form [107]

$$
W_{m t}=-\int_{0}^{s_{1}} 2 \pi r f(s) z d s
$$

was added to Equation (1) where $s_{1}$ is total arc length between the apex and nadir of the NE while $r$ and $z$ corresponding to the abscissa and ordinate of membrane within the load transmission region [107]. Variations of $s_{\mathcal{C}}$ were found to result in the appearance of complex nuclear shapes including tethers, pear, spherical cylinder and dumbbell, in agreement with experimental observations [1-3,107]. Following a similar approach, Castagnetti and coworkers examined how the deformability of chromosomes influences the morphology of 
dividing NE [108]. Specifically, the chromosome was treated as a straight bar bent into a circular arc with curvature $C$, leading to bending energy of chromosomes as

$$
W_{\text {chro }}=\frac{1}{2} k_{\text {chro }} \int C^{2} d s
$$

with $k_{\text {chro }}$ representing the bending rigidity of a chromosome. Note that, in this scene, it was assumed that chromosomes contact with the NE only at two ends (of the bar). It must be pointed out that, besides being widely adopted in examining the morphology of cells or nuclei, the energy minimization approach has also been used in studying problems such as the distribution of NPCs, connecting cytoplasm to the nucleoplasm, on the nuclear membrane $[115,116]$.

(A)



(C)

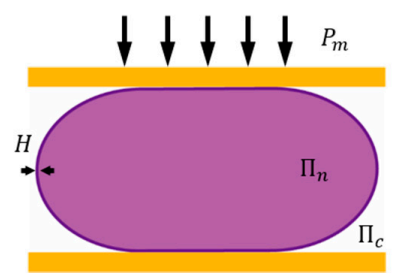

(B)
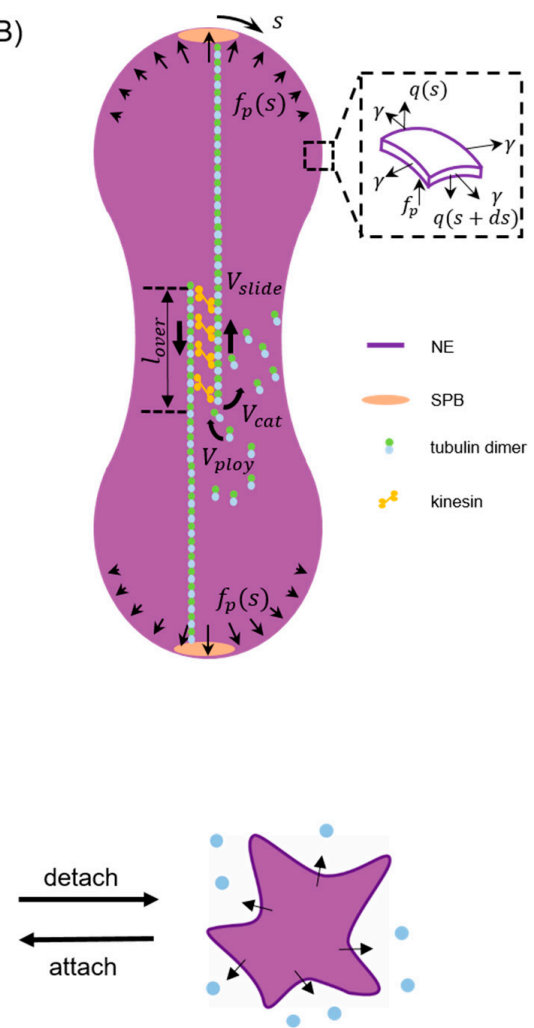

Figure 2. Schematics illustrating typical examples of energy minimization model, boundary integral model and finite element-based model for describing the nuclear envelope (NE) shape change in different cell processes. (A) As the driving force term of closed mitosis in the energy minimization model, a concentrated poleward force $f$ generated by elongating microtubule bundles (green) pushes the two poles of NE to a separation given by $L$ [109]. (B) In the boundary integral model for closed mitosis [117], the NE deformation is assumed to be driven by distributed poleward force $f_{p}$ and resisted by membrane elasticity and viscous drag. Inset shows the forces (membrane tension $\gamma$, transverse shear $q$ and poleward force $f_{p}$ ) acting on the deformed envelope. Here, $s$ represents the arc length coordinate with $s=0$ at the top pole. Microtubule bundles are assumed to have an overlap length $l_{\text {over }}$ where attached kinesin motors can generate forces to slide antiparallel microtubules with a velocity $V_{\text {slide }}$ to effectively push the NE. Meanwhile, the polymerization (with rate $V_{\text {poly }}$ ) and catastrophe-induced disassembly (with rate $V_{\text {cat }}$ ) of microtubules are allowed to take place on their plus ends in the center. (C) In the finite element method (FEM) model describing NE buckling during cell detachment, the perinuclear actin cap and surrounding microtubules are simplified as a compressive plate (orange) and a compression $\left(P_{m}\right)$, respectively. As the detachment goes on, increment of $P_{m}$ results in water (blue dots) efflux from the nucleus, an abrupt increase in the osmotic pressure difference between the nucleoplasm $\left(\Pi_{n}\right)$ and cytoplasm $\left(\Pi_{c}\right)$, and eventually the buckling of NE shell with thickness $H$ [79]. 


\subsection{Boundary Integral Model}

The boundary integral method is well known for its low computation cost due to the reduction in calculation dimensionality (with the use of fundamental solutions) and its efficiency in examining problems like boundary tracking. Since NE serves as a physical barrier to separate cytoplasm from nucleoplasm (both can be viewed as fluid-like or solidlike $[56,117]$ media), it is not surprising to see that boundary integral method has been used to describe its shape evolution. For example, a model was developed recently to examine how the viscous response of cytoplasm [118-120] and nucleoplasm [40,50,121-123] influences the nuclear morphology change during closed mitosis (refer to Figure 2B). Since the Reynolds number involved is small (i.e., $\operatorname{Re}<<1$ ) in this case, the Green's function of Stokes flow can be utilized to express the velocity, along the $i$-th direction, of an arbitrary point $\xi$ on the NE surface $S_{y}$ as $[124,125]$

$$
u_{i}(\xi)=\iint_{S} u_{i}^{j}(\xi, y) n_{j}(y) f(y) d S_{y}
$$

where $u_{i}^{j}(\xi, y)=-\frac{1}{8 \pi \eta}\left(\frac{\delta_{i j}}{r}+\frac{\left(\xi_{i}-y_{i}\right)\left(\xi_{j}-y_{j}\right)}{r^{3}}\right)(i, j=1,2,3)$ is the so-called Stokeslet with $r=|\xi-y|$ and $\eta$ being the viscosity of the nucleoplasm and cytoplasm, and $f$ refers to the force acting on the NE along its normal ( $n$ ) direction, consisting of (i) the poleward force $f_{p}$ generated by kinesin motors residing in the overlap region of microtubule bundles [126,127]; (ii) membrane stretching force $f_{t}$ following Young-Laplace law and (iii) bending-induced transverse shear $f_{b}$ inside the membrane [128], that is

$$
f(y)=f_{p}+f_{t}+f_{b} .
$$

Furthermore, to clarify how kinesin motors and microtubule dynamics are coupled with the elastic deformation of NE and eventually dictate its macroscopic shape change in an explicit manner, classical Hill's law was assumed to describe the relationship between microtubule sliding velocity and generated poleward force [129]. The model predicted that, starting from a sphere, the NE would undergo initial elongation, necking and final spindle poles separation to become a barbell at the end of closed mitosis while defects in microtubules resulting in an abnormal division of the nucleus as observed in experiments. In addition, it was found that the process is dominated by membrane stretching which absorbs $\sim 90 \%$ of the work done by poleward force while the influence of viscosity is negligible.

In contrast, to capture the flattening of fibroblast nucleus during cell spreading, the mixture of cytoplasm and cytoskeleton was treated as a contractile compressible material confined by the plasma membrane and NE [56]. The constitutive relation, in this case, was proposed as

$$
\sigma=2 \eta \dot{\varepsilon}+\sigma_{c} \boldsymbol{I}
$$

where $\sigma$ is the stress tensor, $\eta$ refers to effective viscosity of the material, $\dot{\varepsilon}$ means strain rate tensor, $\sigma_{c}$ is active contractile stress and $I$ represents identity tensor. Meanwhile, four external force terms were considered: (1) nuclear resistance to volume compression/expansion, (2) nuclear resistance to surface area expansion, (3) plasma membrane tension and (4) cell-substrate friction due to actin retrograde flow. In addition, assembly of F-actins was assumed to take place with a rate $v_{a}$ at the cell boundary. Finally, with the help of Kelvin's fundamental solutions for axisymmetric linear elasticity, the velocity field can be obtained by solving the momentum conservation equation $\nabla \cdot \sigma=0$ with the boundary integral method [56]. Interestingly, it was found F-actin assembly at the boundary alone is significant enough to drive the flattening of the cell nucleus while forces induced by microtubules, intermediate filaments, LINC complexes and myosin contraction were all dispensable.

\subsection{Finite Element-Based Models}

Another popular way to model nuclear morphology transformation is to treat the nucleoplasm as an incompressible fluid or a deformable solid enclosed by an elastic shell, 
representing the NE $[49,51,54,55,79,97,98,130,131]$. The finite element method can then be used to implement different constitutive descriptions of the material (in commercial software packages like ANSYS, ABAQUS and COMSOL Multiphysics) to capture the shape change of the nucleus.

An early trial along this direction was made by Varizi and Mofrad more than a decade ago where contributions from different components inside the nucleus on its deformation were examined [54,55]. Specifically, INM, ONM and lamina layer were treated as linear elastic shells with characteristic bending stiffness of the order of $10^{-16} \mathrm{mN} / \mathrm{m}$ and stretching stiffness in the range of $1-10 \mathrm{mN} / \mathrm{m}$. In contrast, the enclosed nucleoplasm was represented by a viscoelastic Maxwell material with a single characteristic relaxation time. Interestingly, it was found that the bending and stretching of NE result in a more diffused stress distribution within the nucleus under AFM indentation, eventually leading to a much reduced maximum effective (von Mises) stress than those predicted by models where the role of NE was neglected. In addition, the force-displacement response was shown to be more sensitive to the nucleoplasm modulus and the bending stiffness of NE than the properties of the lamina layer. Similarly, by treating the NE and lamina layer as an infinitely thin elastic shell wrapping around a compressible elastic solid [49], Hobson and coworkers reported that the nuclear response is governed by nucleoplasm elasticity at small indentation depth but becomes increasingly dominated by stretching of the nuclear membrane as indentation depth increases.

Recently, with the discovery of actin cap formed around the nucleus [7], its role in nuclear shape evolution has also been investigated. For example, to simulate the deformation of nucleus driven by actin polymerization in $\mathrm{T}$ cells, the actin layer and nucleus shell were both treated as isotropic compressible neo-Hookean materials [132] with the strain energy function given by

$$
W=\frac{1}{2} \mu\left(I_{1}-3\right)-\mu \ln J+\frac{1}{2} \lambda(\ln J)^{2}
$$

where $\mu$ and $\lambda$ represent the shear and bulk modulus, respectively. $I_{1}$ is the first invariant of the right Cauchy-Green deformation tensor and $J=\operatorname{det}(\boldsymbol{F})$ with $\boldsymbol{F}$ being the deformation gradient. It was found that, as actin polymerization progresses, the actin layer gradually engulfed the nucleus and then compressed it into an elongated shape. On the other hand, by describing the perinuclear actin cap as a rigid plate to confine the nucleus (refer to Figure 2C), the model was also used to explain the observed NE buckling during cell detachment [79]. In this case, the nuclear volume $\left(V_{n}\right)$ was assumed to change according to the osmotic (i.e., $\Delta \Pi$ which is inversely proportional to $\left.V_{n}\right)$ and hydrostatic $(\Delta P)$ pressure difference across the NE as

$$
\frac{d V_{n}}{d t}=\zeta(\Delta \Pi-\Delta P)
$$

with $\zeta$ representing the water permeability of the membrane. Using this framework, Kim and coworkers showed that, when cell detachment occurs the aggregation of microtubules surrounding the nucleus results in an elevated hydrostatic pressure difference across the nuclear membrane, a water efflux from the nucleus and eventually the buckling of NE itself as observed in experiments [79]. In addition to describing the actin cap as a passive material, active stresses generated within the actin cytoskeleton have also been considered in modeling cell transendothelial migration [97,98], where the nucleus (pulled by actomyosin contraction generated at cell front $[133,134])$ must squeeze through extremely narrow gaps. Specifically, a chemo-mechanical model was introduced to account for the contractile stress $(\sigma)$ as

$$
\sigma=\rho+K \varepsilon
$$


where $\varepsilon, K$ is the strain and effective passive stiffness of the actin filaments, and $\rho$ refers to the force-dipole density (representing active myosin contraction) taking the form

$$
\rho=\frac{\beta \rho_{0}}{\beta-\alpha}+\frac{\alpha K-1}{\beta-\alpha} \varepsilon
$$

with $\rho_{0}$ being the contractility in the absence of adhesions, and $\alpha$ and $\beta$ representing mechano-chemical parameters that arising from the coupling (via Rho-associated protein kinase (ROCK) mediated phosphorylation) between the mechanical stretch of F-actins and the engagement/assembly of myosin motors [135].

Most recently, a more comprehensive model was proposed by Alisafaei and coworkers [131] where almost all biophysical regulators of nuclear shape, like the elastic response of chromatin and NE, anisotropic actomyosin contraction, actin polymerization, focal adhesion and ECM geometry, have been taken into account. In addition to adopting the conventional hyperelastic description of the NE (lamina layer included), i.e.,

$$
\sigma_{i j}=C_{i j k l} \varepsilon_{k l}=\left(C_{i j k l}^{(I)}+C_{i j k l}^{(F)}\right) \varepsilon_{k l}
$$

with $\sigma_{i j}$ and $\varepsilon_{k l}$ being the stress and strain, $C_{i j k l}^{(I)}$ referring to the initial stiffness and $C_{i j k l}^{(F)}$ representing the tension stiffening effect of the lamina network, a similar but more complex mechano-chemical feedback description (compared to Equation (11)) was proposed for capturing the anisotropic actomyosin contraction in the cytoskeleton which was believed to stretch F-actins but compress microtubules, respectively. Interestingly, this model was shown to be capable of explaining a variety of experimental findings, including the ECM geometry regulated actin organization, focal adhesion-induced cytoskeletal alteration and nuclear morphology change [7,57], nuclear invagination [76-78], and cytoskeletonregulated apparent modulus of the nucleus [51].

Finally, we want to emphasize two things. Firstly, the applications of the aforementioned models are far beyond tracking nuclear shape changes. For instance, finite element simulations were also widely used to extract the elastic [41], poroelastic [48,97], hyperelastic [46] or even plastic $[97,130]$ characteristics of the cell nucleus under different experimental and physiological conditions. A typical simulation result revealed that the nucleus is an order of magnitude stiffer than the cytoplasm, consistent with experimental findings $[40,42,136,137]$, and a softer lamina network leads to a higher irreversible deformation of the nucleus as reported in [45]. Secondly, many phenomenological models were not discussed here because they don't fit into the three types of approaches discussed above. For instance, the nucleus has been treated as a standard linear viscoelastic [42] or Voigt-Maxwell [121,122] solid. A mechanical network and semi-analytical models were also proposed to describe nuclear blebbing [138,139] and compression of cell nucleus [140].

\section{Conclusions and Outlooks}

In this review, different theoretical approaches developed to model the nuclear shape transformation during various cellular processes were discussed. When compared with each other, the energy minimization approach can identify the steady-state shape of the NE in a simple and elegant manner, and hence has been widely used in situations where the deformation process is slow (and therefore quasi-static equilibrium of the nuclear membrane can always be assumed). On the other hand, the dynamic nature of the boundary integral approach makes it suitable for cases where the coupling between nucleoskeleton/cytoskeleton dynamics and NE deformation needs to be taken into account. Finally, unlike these two aforementioned approaches, the nonlinear response of the NE (such as its strain-stiffening behavior) can easily be incorporated in finite element-based models. In addition, different constitutive descriptions of the cytoplasm and/or nucleoplasm can also be introduced in finite element-based models (rather than simply treating it as a viscous fluid in boundary integral models or representing its effect as merely providing a volume conservation constraint in the energy minimization approach), allowing us to sys- 
tematically examine how nuclear morphology transformation is influenced by the physical characteristics of these subcellular components.

Despite all the progress mentioned here, several important issues/challenges remain unsettled. First of all, more precise descriptions of the mechanical response of the nucleus and its components are needed. For instance, the nucleoplasm (including chromatins) has been conveniently modelled as a homogeneous elastic [49,108,131], viscoelastic [54,55], poroelastic [97] solid or a viscous fluid $[79,117]$ in different studies. In reality, it is conceivable that deformation of the nuclear envelope will squeeze/distort the chromatins inside which can then in return affect the deformability of the nucleus as a whole. In addition, condensation of chromatin can also take place during the cell cycle and therefore alter the mechanical properties of the nucleus. More realistic models are needed in the future to take these important factors into account.

Furthermore, a unified model capable of incorporating detailed environmental/cellular/ nuclear structures in influencing the nuclear morphology is still lacking. As can be seen from this review, the nucleus was often treated as a homogeneous body in the early years before the nuclear membrane was modelled separately from the nucleoplasm. After the discovery of the actin cap, descriptions of cytoskeleton started to appear in different models to highlight its important regulatory role. Recently, attempts of including focal adhesion and active mechano-chemical feedback into the model have also been made. In the future, given that most deformations of the nucleus were caused by forces generated within the cytoskeleton or nucleoskeleton, analyzing the interactions between nuclear membrane and growing/evolving bio-filaments will likely be another key for modeling NE shape change, similar to that in examining cell migration [141-143] and filopodium formation [144-146] where cellular movement is known to be driven by the polymerizing F-atcin network. Although microtubule dynamics and macroscopic deformation of nuclear membrane during closed mitosis were connected together in a simple manner by the boundary integral model proposed recently [117], a much more concentrated effort is needed to extend this to other processes.

Lastly, by revealing the biophysical mechanisms behind them, modelling works are expected to go beyond explaining observations to provide insights for the design of future experiments and biomedical applications. Actually, many assumptions made in the models discussed above came from and evolved with experimental observations. For example, the propelling force from separating microtubules during closed mitosis was regarded as a concentrated one initially $[108,109]$. As evidence emerged showing that chromosomes could bind to INM (and therefore presumably transmit load), such force was then modified to be distributed on the NE $[107,117]$. Similarly, linear elastic description of NE was adopted in the early days [55] which was then improved to be hyperelastic to reflect the widely observed strain-stiffening behavior of biological tissues [147-149]. On the other hand, modelling works have helped experimentalists to design new experiments or catch important phenomena that went unnoticed previously. For instance, Li and coworkers theoretically found spreading itself is enough to drive the nucleus flattening without the help of other factors [56]. This prediction then likely led Patteson and coworkers to carry out further experimental investigations to examine the correlation between the spreading level and nuclear sphericity in $\mathrm{vim}^{+} / \mathrm{vim}^{-}$cells [82]. Another example is the predicted sudden necking of NE during closed mitosis, a phenomenon that often went unnoticed in dividing yeast cells before this prediction was reported [117]. On the application front, it is conceivable that combining modelling with machine learning could potentially lead to strategies for the diagnosis and prognosis of cancers and laminopathies [150,151] where the abnormal nuclear shape is realized as a disease marker [22]. This is certainly an important direction that warrants investigations in the future.

Author Contributions: Conceptualization, Y.L.; investigation, C.F.; writing-original draft preparation, C.F. and Y.L.; writing-review and editing, C.F., J.Y., X.X. and Y.L.; visualization, C.F.; supervision, Y.L.; project administration, Y.L.; funding acquisition, Y.L. All authors have read and agreed to the published version of the manuscript. 
Funding: This research was funded by the Research Grants Council of the Hong Kong Special Administration Region, grant number GRF/17210618, GRF/17210520; and the National Natural Science Foundation of China, grant number 11872325.

Institutional Review Board Statement: Not applicable.

Informed Consent Statement: Not applicable.

Data Availability Statement: Not applicable.

Conflicts of Interest: The authors declare no conflict of interest.

\section{References}

1. Zheng, L.; Schwartz, C.; Magidson, V.; Khodjakov, A.; Oliferenko, S. The spindle pole bodies facilitate nuclear envelope division during closed mitosis in fission yeast. PLoS Biol. 2007, 5, e170. [CrossRef]

2. Gonzalez, Y.; Meerbrey, K.; Chong, J.; Torii, Y.; Padte, N.N.; Sazer, S. Nuclear shape, growth and integrity in the closed mitosis of fission yeast depend on the Ran-GTPase system, the spindle pole body and the endoplasmic reticulum. J. Cell Sci. 2009, 122, 2464-2472. [CrossRef]

3. Yam, C.; He, Y.; Zhang, D.; Chiam, K.-H.; Oliferenko, S. Divergent strategies for controlling the nuclear membrane satisfy geometric constraints during nuclear division. Curr. Biol. 2011, 21, 1314-1319. [CrossRef] [PubMed]

4. Kim, J.-K.; Louhghalam, A.; Lee, G.; Schafer, B.W.; Wirtz, D.; Kim, D.-H. Nuclear lamin A/C harnesses the perinuclear apical actin cables to protect nuclear morphology. Nat. Commun. 2017, 8, 1-13. [CrossRef]

5. Vishavkarma, R.; Raghavan, S.; Kuyyamudi, C.; Majumder, A.; Dhawan, J.; Pullarkat, P.A. Role of actin filaments in correlating nuclear shape and cell spreading. PLoS ONE 2014, 9, e107895.

6. Lovett, D.B.; Shekhar, N.; Nickerson, J.A.; Roux, K.J.; Lele, T.P. Modulation of nuclear shape by substrate rigidity. Cell. Mol. Bioeng. 2013, 6, 230-238. [CrossRef]

7. Khatau, S.B.; Hale, C.M.; Stewart-Hutchinson, P.J.; Patel, M.S.; Stewart, C.L.; Searson, P.C.; Hodzic, D.; Wirtz, D. A perinuclear actin cap regulates nuclear shape. Proc. Natl. Acad. Sci. USA 2009, 106, 19017-19022. [CrossRef] [PubMed]

8. Davidson, P.M.; Denais, C.; Bakshi, M.C.; Lammerding, J. Nuclear deformability constitutes a rate-limiting step during cell migration in 3-D environments. Cell. Mol. Bioeng. 2014, 7, 293-306. [CrossRef]

9. Giverso, C.; Grillo, A.; Preziosi, L. Influence of nucleus deformability on cell entry into cylindrical structures. Biomech. Model. Mechanobiol. 2014, 13, 481-502. [CrossRef]

10. Lomakin, A.; Cattin, C.; Cuvelier, D.; Alraies, Z.; Molina, M.; Nader, G.; Srivastava, N.; Saez, P.; Garcia-Arcos, J.; Zhitnyak, I. The nucleus acts as a ruler tailoring cell responses to spatial constraints. Science 2020, 370, eaba2894. [CrossRef]

11. Venturini, V.; Pezzano, F.; Castro, F.C.; Häkkinen, H.-M.; Jiménez-Delgado, S.; Colomer-Rosell, M.; Marro, M.; Tolosa-Ramon, Q.; Paz-López, S.; Valverde, M.A. The nucleus measures shape changes for cellular proprioception to control dynamic cell behavior. Science 2020, 370, eaba2644. [CrossRef]

12. Lee, H.-P.; Alisafaei, F.; Adebawale, K.; Chang, J.; Shenoy, V.B.; Chaudhuri, O. The nuclear piston activates mechanosensitive ion channels to generate cell migration paths in confining microenvironments. Sci. Adv. 2021, 7, eabd4058. [CrossRef]

13. Sazer, S.; Lynch, M.; Needleman, D. Deciphering the evolutionary history of open and closed mitosis. Curr. Biol. 2014, 24, R1099-R1103. [CrossRef]

14. Smoyer, C.J.; Jaspersen, S.L. Breaking down the wall: The nuclear envelope during mitosis. Curr. Opin. Cell Biol. 2014, 26, 1-9. [CrossRef]

15. Dey, G.; Culley, S.; Curran, S.; Schmidt, U.; Henriques, R.; Kukulski, W.; Baum, B. Closed mitosis requires local disassembly of the nuclear envelope. Nature 2020, 585, 119-123. [CrossRef]

16. Qu, L.-H.; Sun, M.-X. The plant cell nucleus is constantly alert and highly sensitive to repetitive local mechanical stimulations. Plant Cell Rep. 2007, 26, 1187-1193. [CrossRef]

17. Xiong, T.C.; Jauneau, A.; Ranjeva, R.; Mazars, C. Isolated plant nuclei as mechanical and thermal sensors involved in calcium signalling. Plant J. 2004, 40, 12-21. [CrossRef]

18. Kirby, T.J.; Lammerding, J. Emerging views of the nucleus as a cellular mechanosensor. Nat. Cell Biol. 2018, 20, 373-381. [CrossRef]

19. Cho, S.; Irianto, J.; Discher, D.E. Mechanosensing by the nucleus: From pathways to scaling relationships. J. Cell Biol. 2017, 216, 305-315. [CrossRef]

20. Enyedi, B.; Jelcic, M.; Niethammer, P. The cell nucleus serves as a mechanotransducer of tissue damage-induced inflammation. Cell 2016, 165, 1160-1170. [CrossRef]

21. Enyedi, B.; Niethammer, P. Nuclear membrane stretch and its role in mechanotransduction. Nucleus 2017, 8, 156-161. [CrossRef]

22. Uhler, C.; Shivashankar, G. Nuclear mechanopathology and cancer diagnosis. Trends Cancer 2018, 4, 320-331. [CrossRef]

23. Maurer, M.; Lammerding, J. The driving force: Nuclear mechanotransduction in cellular function, fate, and disease. Annu. Rev. Biomed. Eng. 2019, 21, 443-468. [CrossRef] [PubMed]

24. Uhler, C.; Shivashankar, G. Regulation of genome organization and gene expression by nuclear mechanotransduction. Nat. Rev. Mol. Cell Biol. 2017, 18, 717-727. [CrossRef] 
25. Jain, N.; Iyer, K.V.; Kumar, A.; Shivashankar, G. Cell geometric constraints induce modular gene-expression patterns via redistribution of HDAC3 regulated by actomyosin contractility. Proc. Natl. Acad. Sci. USA 2013, 110, 11349-11354. [CrossRef]

26. Gupta, S.; Marcel, N.; Sarin, A.; Shivashankar, G. Role of actin dependent nuclear deformation in regulating early gene expression. PLoS ONE 2012, 7, e53031. [CrossRef]

27. Obara, K.; Kuriyama, H.; Fukuda, H. Direct evidence of active and rapid nuclear degradation triggered by vacuole rupture during programmed cell death in Zinnia. Plant Physiol. 2001, 125, 615-626. [CrossRef] [PubMed]

28. Kost, B.; Chua, N.-H. The plant cytoskeleton: Vacuoles and cell walls make the difference. Cell 2002, 108, 9-12. [CrossRef]

29. Zink, D.; Fischer, A.H.; Nickerson, J.A. Nuclear structure in cancer cells. Nat. Rev. Cancer 2004, 4, 677-687. [CrossRef] [PubMed]

30. Zwerger, M.; Ho, C.Y.; Lammerding, J. Nuclear mechanics in disease. Annu. Rev. Biomed. Eng. 2011, 13, 397-428. [CrossRef]

31. De Sandre-Giovannoli, A.; Bernard, R.; Cau, P.; Navarro, C.; Amiel, J.; Boccaccio, I.; Lyonnet, S.; Stewart, C.L.; Munnich, A.; Le Merrer, M. Lamin a truncation in Hutchinson-Gilford progeria. Science 2003, 300, 2055. [CrossRef]

32. Eriksson, M.; Brown, W.T.; Gordon, L.B.; Glynn, M.W.; Singer, J.; Scott, L.; Erdos, M.R.; Robbins, C.M.; Moses, T.Y.; Berglund, P. Recurrent de novo point mutations in lamin A cause Hutchinson-Gilford progeria syndrome. Nature 2003, 423, $293-298$. [CrossRef]

33. Goldman, R.D.; Shumaker, D.K.; Erdos, M.R.; Eriksson, M.; Goldman, A.E.; Gordon, L.B.; Gruenbaum, Y.; Khuon, S.; Mendez, M.; Varga, R. Accumulation of mutant lamin A causes progressive changes in nuclear architecture in Hutchinson-Gilford progeria syndrome. Proc. Natl. Acad. Sci. USA 2004, 101, 8963-8968. [CrossRef]

34. Ghosh, S.; Zhou, Z. Genetics of aging, progeria and lamin disorders. Curr. Opin. Genet. Dev. 2014, 26, 41-46. [CrossRef]

35. Lele, T.P.; Dickinson, R.B.; Gundersen, G.G. Mechanical principles of nuclear shaping and positioning. J. Cell Biol. 2018, 217, 3330-3342. [CrossRef]

36. Dahl, K.N.; Scaffidi, P.; Islam, M.F.; Yodh, A.G.; Wilson, K.L.; Misteli, T. Distinct structural and mechanical properties of the nuclear lamina in Hutchinson-Gilford progeria syndrome. Proc. Natl. Acad. Sci. USA 2006, 103, 10271-10276. [CrossRef]

37. Bione, S.; Maestrini, E.; Rivella, S.; Mancini, M.; Regis, S.; Romeo, G.; Toniolo, D. Identification of a novel X-linked gene responsible for Emery-Dreifuss muscular dystrophy. Nat. Genet. 1994, 8, 323-327. [CrossRef]

38. Rowat, A.; Lammerding, J.; Ipsen, J.H. Mechanical properties of the cell nucleus and the effect of emerin deficiency. Biophys. J. 2006, 91, 4649-4664. [CrossRef]

39. Lammerding, J.; Hsiao, J.; Schulze, P.C.; Kozlov, S.; Stewart, C.L.; Lee, R.T. Abnormal nuclear shape and impaired mechanotransduction in emerin-deficient cells. J. Cell Biol. 2005, 170, 781-791. [CrossRef]

40. Tseng, Y.; Lee, J.S.; Kole, T.P.; Jiang, I.; Wirtz, D. Micro-organization and visco-elasticity of the interphase nucleus revealed by particle nanotracking. J. Cell Sci. 2004, 117, 2159-2167. [CrossRef]

41. Lherbette, M.; Dos Santos, Á.; Hari-Gupta, Y.; Fili, N.; Toseland, C.P.; Schaap, I.A. Atomic Force Microscopy micro-rheology reveals large structural inhomogeneities in single cell-nuclei. Sci. Rep. 2017, 7, 1-13. [CrossRef] [PubMed]

42. Guilak, F.; Tedrow, J.R.; Burgkart, R. Viscoelastic properties of the cell nucleus. Biochem. Biophys. Res. Commun. 2000, 269, 781-786. [CrossRef] [PubMed]

43. Deguchi, S.; Maeda, K.; Ohashi, T.; Sato, M. Flow-induced hardening of endothelial nucleus as an intracellular stress-bearing organelle. J. Biomech. 2005, 38, 1751-1759. [CrossRef] [PubMed]

44. Rowat, A.C.; Foster, L.J.; Nielsen, M.M.; Weiss, M.; Ipsen, J.H. Characterization of the elastic properties of the nuclear envelope. J. R. Soc. Interface 2005, 2, 63-69. [CrossRef]

45. Pajerowski, J.D.; Dahl, K.N.; Zhong, F.L.; Sammak, P.J.; Discher, D.E. Physical plasticity of the nucleus in stem cell differentiation. Proc. Natl. Acad. Sci. USA 2007, 104, 15619-15624. [CrossRef]

46. Caille, N.; Thoumine, O.; Tardy, Y.; Meister, J.-J. Contribution of the nucleus to the mechanical properties of endothelial cells. J. Biomech. 2002, 35, 177-187. [CrossRef]

47. Stephens, A.D.; Banigan, E.J.; Adam, S.A.; Goldman, R.D.; Marko, J.F. Chromatin and lamin A determine two different mechanical response regimes of the cell nucleus. Mol. Biol. Cell 2017, 28, 1984-1996. [CrossRef]

48. Wei, F.; Lan, F.; Liu, B.; Liu, L.; Li, G. Poroelasticity of cell nuclei revealed through atomic force microscopy characterization. Appl. Phys. Lett. 2016, 109, 213701. [CrossRef]

49. Hobson, C.M.; Kern, M.; O’Brien, E.T.; Stephens, A.D.; Falvo, M.R.; Superfine, R. Correlating nuclear morphology and external force with combined atomic force microscopy and light sheet imaging separates roles of chromatin and lamin A/C in nuclear mechanics. Mol. Biol. Cell 2020, 31, 1788-1801. [CrossRef]

50. Liang, L.; Wang, X.; Da, X.; Chen, T.; Chen, W.R. Noninvasive determination of cell nucleoplasmic viscosity by fluorescence correlation spectroscopy. J. Biomed. Opt. 2009, 14, 024013. [CrossRef]

51. Zhang, J.; Alisafaei, F.; Nikolić, M.; Nou, X.A.; Kim, H.; Shenoy, V.B.; Scarcelli, G. Nuclear mechanics within intact cells is regulated by cytoskeletal network and internal nanostructures. Small 2020, 16, 1907688. [CrossRef] [PubMed]

52. Schreiner, S.M.; Koo, P.K.; Zhao, Y.; Mochrie, S.G.; King, M.C. The tethering of chromatin to the nuclear envelope supports nuclear mechanics. Nat. Commun. 2015, 6, 7159. [CrossRef]

53. Khodjakov, A.; La Terra, S.; Chang, F. Laser microsurgery in fission yeast: Role of the mitotic spindle midzone in anaphase B. Curr. Biol. 2004, 14, 1330-1340. [CrossRef]

54. Vaziri, A.; Mofrad, M.R.K. Mechanics and deformation of the nucleus in micropipette aspiration experiment. J. Biomech. 2007, 40, 2053-2062. [CrossRef] [PubMed] 
55. Vaziri, A.; Lee, H.; Mofrad, M.K. Deformation of the cell nucleus under indentation: Mechanics and mechanisms. J. Mater. Res. 2006, 21, 2126-2135. [CrossRef]

56. Li, Y.; Lovett, D.; Zhang, Q.; Neelam, S.; Kuchibhotla, R.A.; Zhu, R.; Gundersen, G.G.; Lele, T.P.; Dickinson, R.B. Moving cell boundaries drive nuclear shaping during cell spreading. Biophys. J. 2015, 109, 670-686. [CrossRef]

57. Versaevel, M.; Grevesse, T.; Gabriele, S. Spatial coordination between cell and nuclear shape within micropatterned endothelial cells. Nat. Commun. 2012, 3,1-11. [CrossRef]

58. Hobson, C.M.; Stephens, A.D. Modeling of Cell Nuclear Mechanics: Classes, Components, and Applications. Cells 2020, 9 , 1623. [CrossRef]

59. Alberts, B.; Johnson, A.; Lewis, J.; Morgan, D.; Raff, M.; Roberts, K.; Walter, P. Molecular Biology of the Cell, 6th ed.; Garland Science: New York, NY, USA, 2015; p. 180.

60. Franke, W.W.; Scheer, U.; Krohne, G.; Jarasch, E.-D. The nuclear envelope and the architecture of the nuclear periphery. J. Cell Biol. 1981, 91, 39s-50s. [CrossRef]

61. D'angelo, M.A.; Anderson, D.J.; Richard, E.; Hetzer, M.W. Nuclear pores form de novo from both sides of the nuclear envelope. Science 2006, 312, 440-443. [CrossRef]

62. De Magistris, P.; Antonin, W. The dynamic nature of the nuclear envelope. Curr. Biol. 2018, 28, R487-R497. [CrossRef]

63. Senda, T.; Iizuka-Kogo, A.; Shimomura, A. Visualization of the nuclear lamina in mouse anterior pituitary cells and immunocytochemical detection of lamin A/C by quick-freeze freeze-substitution electron microscopy. J. Histochem. Cytochem. 2005, 53, 497-507. [CrossRef] [PubMed]

64. Mans, B.; Anantharaman, V.; Aravind, L.; Koonin, E.V. Comparative genomics, evolution and origins of the nuclear envelope and nuclear pore complex. Cell Cycle 2004, 3, 1625-1650. [CrossRef]

65. Jahed, Z.; Mofrad, M.R. The nucleus feels the force, LINCed in or not! Curr. Opin. Cell Biol. 2019, 58, 114-119. [CrossRef] [PubMed]

66. Agrawal, A.; Lele, T.P. Mechanics of nuclear membranes. J. Cell Sci. 2019, 132, jcs229245. [CrossRef]

67. Jevtić, P.; Edens, L.J.; Vuković, L.D.; Levy, D.L. Sizing and shaping the nucleus: Mechanisms and significance. Curr. Opin. Cell Biol. 2014, 28, 16-27. [CrossRef]

68. Chalut, K.J.; Höpfler, M.; Lautenschläger, F.; Boyde, L.; Chan, C.J.; Ekpenyong, A.; Martinez-Arias, A.; Guck, J. Chromatin decondensation and nuclear softening accompany Nanog downregulation in embryonic stem cells. Biophys. J. 2012, 103, 2060-2070. [CrossRef]

69. Furusawa, T.; Rochman, M.; Taher, L.; Dimitriadis, E.K.; Nagashima, K.; Anderson, S.; Bustin, M. Chromatin decompaction by the nucleosomal binding protein HMGN5 impairs nuclear sturdiness. Nat. Commun. 2015, 6, 6138. [CrossRef]

70. Zhang, Q.; Ragnauth, C.; Greener, M.J.; Shanahan, C.M.; Roberts, R.G. The nesprins are giant actin-binding proteins, orthologous to Drosophila melanogaster muscle protein MSP-300. Genomics 2002, 80, 473-481. [CrossRef] [PubMed]

71. Dahl, K.N.; Ribeiro, A.J.; Lammerding, J. Nuclear shape, mechanics, and mechanotransduction. Circ. Res. 2008, 102, 1307-1318. [CrossRef]

72. Fan, J.; Beck, K.A. A role for the spectrin superfamily member Syne-1 and kinesin II in cytokinesis. J. Cell Sci. 2004, 117, 619-629. [CrossRef]

73. Wilhelmsen, K.; Litjens, S.H.; Kuikman, I.; Tshimbalanga, N.; Janssen, H.; van den Bout, I.; Raymond, K.; Sonnenberg, A. Nesprin-3, a novel outer nuclear membrane protein, associates with the cytoskeletal linker protein plectin. J. Cell Biol. 2005, 171, 799-810. [CrossRef]

74. Sun, D.; Leung, C.L.; Liem, R. Characterization of the microtubule binding domain of microtubule actin crosslinking factor (MACF): Identification of a novel group of microtubule associated proteins. J. Cell Sci. 2001, 114, 161-172. [CrossRef] [PubMed]

75. Wiche, G. Role of plectin in cytoskeleton organization and dynamics. J. Cell Sci. 1998, 111, 2477-2486. [CrossRef]

76. Zhao, T.; Graham, O.S.; Raposo, A.; St Johnston, D. Growing microtubules push the oocyte nucleus to polarize the Drosophila dorsal-ventral axis. Science 2012, 336, 999-1003. [CrossRef] [PubMed]

77. Hampoelz, B.; Azou-Gros, Y.; Fabre, R.; Markova, O.; Puech, P.-H.; Lecuit, T. Microtubule-induced nuclear envelope fluctuations control chromatin dynamics in Drosophila embryos. Development 2011, 138, 3377-3386. [CrossRef] [PubMed]

78. Gerlitz, G.; Reiner, O.; Bustin, M. Microtubule dynamics alter the interphase nucleus. Cell. Mol. Life Sci. 2013, 70, 1255-1268. [CrossRef] [PubMed]

79. Kim, D.-H.; Li, B.; Si, F.; Phillip, J.M.; Wirtz, D.; Sun, S.X. Volume regulation and shape bifurcation in the cell nucleus. J. Cell Sci. 2015, 128, 3375-3385. [CrossRef]

80. Kim, D.-H.; Cho, S.; Wirtz, D. Tight coupling between nucleus and cell migration through the perinuclear actin cap. J. Cell Sci. 2014, 127, 2528-2541.

81. Kim, D.-H.; Chambliss, A.B.; Wirtz, D. The multi-faceted role of the actin cap in cellular mechanosensation and mechanotransduction. Soft Matter 2013, 9, 5516-5523. [CrossRef] [PubMed]

82. Patteson, A.E.; Vahabikashi, A.; Pogoda, K.; Adam, S.A.; Mandal, K.; Kittisopikul, M.; Sivagurunathan, S.; Goldman, A.; Goldman, R.D.; Janmey, P.A. Vimentin protects cells against nuclear rupture and DNA damage during migration. J. Cell Biol. 2019, 218, 4079-4092. [CrossRef] [PubMed]

83. Lowery, J.; Kuczmarski, E.R.; Herrmann, H.; Goldman, R.D. Intermediate filaments play a pivotal role in regulating cell architecture and function. J. Biol. Chem. 2015, 290, 17145-17153. [CrossRef] [PubMed] 
84. Sarria, A.J.; Lieber, J.G.; Nordeen, S.K.; Evans, R.M. The presence or absence of a vimentin-type intermediate filament network affects the shape of the nucleus in human SW-13 cells. J. Cell Sci. 1994, 107, 1593-1607. [CrossRef]

85. Trichet, L.; Le Digabel, J.; Hawkins, R.J.; Vedula, S.R.K.; Gupta, M.; Ribrault, C.; Hersen, P.; Voituriez, R.; Ladoux, B. Evidence of a large-scale mechanosensing mechanism for cellular adaptation to substrate stiffness. Proc. Natl. Acad. Sci. USA 2012, 109, 6933-6938. [CrossRef]

86. Elosegui-Artola, A.; Oria, R.; Chen, Y.; Kosmalska, A.; Pérez-González, C.; Castro, N.; Zhu, C.; Trepat, X.; Roca-Cusachs, P. Mechanical regulation of a molecular clutch defines force transmission and transduction in response to matrix rigidity. Nat. Cell Biol. 2016, 18, 540. [CrossRef]

87. Lo, C.-M.; Wang, H.-B.; Dembo, M.; Wang, Y.-1. Cell movement is guided by the rigidity of the substrate. Biophys. J. 2000, 79, 144-152. [CrossRef]

88. Engler, A.; Bacakova, L.; Newman, C.; Hategan, A.; Griffin, M.; Discher, D. Substrate compliance versus ligand density in cell on gel responses. Biophys. J. 2004, 86, 617-628. [CrossRef]

89. Prager-Khoutorsky, M.; Lichtenstein, A.; Krishnan, R.; Rajendran, K.; Mayo, A.; Kam, Z.; Geiger, B.; Bershadsky, A.D. Fibroblast polarization is a matrix-rigidity-dependent process controlled by focal adhesion mechanosensing. Nat. Cell Biol. 2011, 13, 1457-1465. [CrossRef]

90. Doss, B.L.; Pan, M.; Gupta, M.; Grenci, G.; Mège, R.-M.; Lim, C.T.; Sheetz, M.P.; Voituriez, R.; Ladoux, B. Cell response to substrate rigidity is regulated by active and passive cytoskeletal stress. Proc. Natl. Acad. Sci. USA 2020, 117, 12817-12825. [CrossRef] [PubMed]

91. Discher, D.E.; Janmey, P.; Wang, Y.-1. Tissue cells feel and respond to the stiffness of their substrate. Science 2005, 310, 1139-1143. [CrossRef] [PubMed]

92. Théry, M.; Racine, V.; Piel, M.; Pépin, A.; Dimitrov, A.; Chen, Y.; Sibarita, J.-B.; Bornens, M. Anisotropy of cell adhesive microenvironment governs cell internal organization and orientation of polarity. Proc. Natl. Acad. Sci. USA 2006, 103, 19771-19776. [CrossRef] [PubMed]

93. Kanchanawong, P.; Shtengel, G.; Pasapera, A.M.; Ramko, E.B.; Davidson, M.W.; Hess, H.F.; Waterman, C.M. Nanoscale architecture of integrin-based cell adhesions. Nature 2010, 468, 580. [CrossRef] [PubMed]

94. Dupin, I.; Camand, E.; Etienne-Manneville, S. Classical cadherins control nucleus and centrosome position and cell polarity. J. Cell Biol. 2009, 185, 779-786. [CrossRef]

95. Arias-Garcia, M.; Rickman, R.; Sero, J.; Yuan, Y.; Bakal, C. The cell-cell adhesion protein JAM3 determines nuclear deformability by regulating microtubule organization. bioRxiv 2020, 689737. [CrossRef]

96. Wolf, K.; Te Lindert, M.; Krause, M.; Alexander, S.; Te Riet, J.; Willis, A.L.; Hoffman, R.M.; Figdor, C.G.; Weiss, S.J.; Friedl, P. Physical limits of cell migration: Control by ECM space and nuclear deformation and tuning by proteolysis and traction force. $J$. Cell Biol. 2013, 201, 1069-1084. [CrossRef]

97. Cao, X.; Moeendarbary, E.; Isermann, P.; Davidson, P.M.; Wang, X.; Chen, M.B.; Burkart, A.K.; Lammerding, J.; Kamm, R.D.; Shenoy, V.B. A chemomechanical model for nuclear morphology and stresses during cell transendothelial migration. Biophys. J. 2016, 111, 1541-1552. [CrossRef]

98. Heo, S.-J.; Song, K.H.; Thakur, S.; Miller, L.M.; Cao, X.; Peredo, A.P.; Seiber, B.N.; Qu, F.; Driscoll, T.P.; Shenoy, V.B. Nuclear softening expedites interstitial cell migration in fibrous networks and dense connective tissues. Sci. Adv. 2020, 6, eaax5083. [CrossRef]

99. Pullarkat, P.A.; Dommersnes, P.; Fernández, P.; Joanny, J.-F.; Ott, A. Osmotically driven shape transformations in axons. Phys. Rev. Lett. 2006, 96, 048104. [CrossRef]

100. Hui, T.H.; Kwan, K.W.; Yip, T.T.C.; Fong, H.W.; Ngan, K.C.; Yu, M.; Yao, S.; Ngan, A.H.W.; Lin, Y. Regulating the Membrane Transport Activity and Death of Cells via Electroosmotic Manipulation. Biophys. J. 2016, 110, 2769-2778. [CrossRef]

101. Stroka, K.M.; Jiang, H.; Chen, S.-H.; Tong, Z.; Wirtz, D.; Sun, S.X.; Konstantopoulos, K. Water permeation drives tumor cell migration in confined microenvironments. Cell 2014, 157, 611-623. [CrossRef]

102. Yang, Y.; Jiang, H. Shape and dynamics of adhesive cells: Mechanical response of open systems. Phys. Rev. Lett. 2017, 118, 208102. [CrossRef] [PubMed]

103. Li, Y.; Yao, L.; Mori, Y.; Sun, S.X. On the energy efficiency of cell migration in diverse physical environments. Proc. Natl. Acad. Sci. USA 2019, 116, 23894-23900. [CrossRef]

104. Finan, J.D.; Chalut, K.J.; Wax, A.; Guilak, F. Nonlinear osmotic properties of the cell nucleus. Ann. Biomed. Eng. 2009, $37,477$. [CrossRef] [PubMed]

105. Canham, P.B. The minimum energy of bending as a possible explanation of the biconcave shape of the human red blood cell. J. Theor. Biol. 1970, 26, 61-81. [CrossRef]

106. Helfrich, W. Elastic properties of lipid bilayers: Theory and possible experiments. Z. Naturforsch. C 1973, 28, 693-703. [CrossRef]

107. Zhu, Q.; Zheng, F.; Liu, A.P.; Qian, J.; Fu, C.; Lin, Y. Shape Transformation of the Nuclear Envelope during Closed Mitosis. Biophys. J. 2016, 111, 2309-2316. [CrossRef]

108. Castagnetti, S.; Božič, B.; Svetina, S. Mechanical and molecular basis for the symmetrical division of the fission yeast nuclear envelope. Phys. Chem. Chem. Phys. 2015, 17, 15629-15636. [CrossRef]

109. Lim, H.W.G.; Huber, G.; Torii, Y.; Hirata, A.; Miller, J.; Sazer, S. Vesicle-like biomechanics governs important aspects of nuclear geometry in fission yeast. PLoS ONE 2007, 2, e948. [CrossRef] 
110. Emsellem, V.; Cardoso, O.; Tabeling, P. Vesicle deformation by microtubules: A phase diagram. Phys. Rev. E 1998, $58,4807$. [CrossRef]

111. Seifert, U. Configurations of fluid membranes and vesicles. Adv. Phys. 1997, 46, 13-137. [CrossRef]

112. Evans, E.A. Minimum energy analysis of membrane deformation applied to pipet aspiration and surface adhesion of red blood cells. Biophys. J. 1980, 30, 265-284. [CrossRef]

113. Gonzalez, Y.; Saito, A.; Sazer, S. Fission yeast Lem2 and Man1 perform fundamental functions of the animal cell nuclear lamina. Nucleus 2012, 3, 60-76. [CrossRef]

114. King, M.C.; Lusk, C.; Blobel, G. Karyopherin-mediated import of integral inner nuclear membrane proteins. Nature 2006, 442, 1003-1007. [CrossRef] [PubMed]

115. Torbati, M.; Lele, T.P.; Agrawal, A. Ultradonut topology of the nuclear envelope. Proc. Natl. Acad. Sci. USA 2016, 113, 11094-11099. [CrossRef] [PubMed]

116. Noguchi, H. Construction of nuclear envelope shape by a high-genus vesicle with pore-size constraint. Biophys. J. 2016, 111, 824-831. [CrossRef] [PubMed]

117. Fang, C.; Zheng, F.; Yao, J.; Wei, X.; Fu, C.; Shi, X.; Lin, Y. A Model for Bridging Microtubule Dynamics with Nuclear Envelope Shape Evolution during Closed Mitosis. J. Mech. Phys. Solids 2020, 144, 104116. [CrossRef]

118. Daniels, B.R.; Masi, B.C.; Wirtz, D. Probing single-cell micromechanics in vivo: The microrheology of C. elegans developing embryos. Biophys. J. 2006, 90, 4712-4719. [CrossRef] [PubMed]

119. Wirtz, D. Particle-tracking microrheology of living cells: Principles and applications. Annu. Rev. Biophys. 2009, 38, 301-326. [CrossRef]

120. Doubrovinski, K.; Swan, M.; Polyakov, O.; Wieschaus, E.F. Measurement of cortical elasticity in Drosophila melanogaster embryos using ferrofluids. Proc. Natl. Acad. Sci. USA 2017, 114, 1051-1056. [CrossRef]

121. de Vries, A.H.; Krenn, B.E.; van Driel, R.; Subramaniam, V.; Kanger, J.S. Direct observation of nanomechanical properties of chromatin in living cells. Nano Lett. 2007, 7, 1424-1427. [CrossRef]

122. Celedon, A.; Hale, C.M.; Wirtz, D. Magnetic manipulation of nanorods in the nucleus of living cells. Biophys. J. 2011, 101, 1880-1886. [CrossRef] [PubMed]

123. Caragine, C.M.; Haley, S.C.; Zidovska, A. Surface fluctuations and coalescence of nucleolar droplets in the human cell nucleus. Phys. Rev. Lett. 2018, 121, 148101. [CrossRef] [PubMed]

124. Power, H.; Wrobel, L.C. Boundary Integral Methods in Fluid Mechanics; Computational Mechanics: Southampton, UK, 1995; pp. 247-250.

125. Pozrikidis, C. Boundary Integral and Singularity Methods for Linearized Viscous Flow; Cambridge University Press: New York, NY, USA, 1992; pp. 143-144.

126. Brust-Mascher, I.; Civelekoglu-Scholey, G.; Kwon, M.; Mogilner, A.; Scholey, J.M. Model for anaphase B: Role of three mitotic motors in a switch from poleward flux to spindle elongation. Proc. Natl. Acad. Sci. USA 2004, 101, 15938-15943. [CrossRef]

127. Brust-Mascher, I.; Scholey, J.M. Mitotic motors and chromosome segregation: The mechanism of anaphase B. Biochem. Soc. Trans. 2011, 39, 1149-1153. [CrossRef] [PubMed]

128. Pozrikidis, C. Effect of membrane bending stiffness on the deformation of capsules in simple shear flow. J. Fluid Mech. 2001, 440, 269-291. [CrossRef]

129. Hill, A.V. The heat of shortening and the dynamic constants of muscle. Proc. Royal Soc. B 1938, 126, $136-195$.

130. Deveraux, S.; Allena, R.; Aubry, D. A numerical model suggests the interplay between nuclear plasticity and stiffness during a perfusion assay. J. Theor. Biol. 2017, 435, 62-77. [CrossRef]

131. Alisafaei, F.; Jokhun, D.S.; Shivashankar, G.; Shenoy, V.B. Regulation of nuclear architecture, mechanics, and nucleocytoplasmic shuttling of epigenetic factors by cell geometric constraints. Proc. Natl. Acad. Sci. USA 2019, 116, 13200-13209. [CrossRef]

132. Fabrikant, G.; Gupta, S.; Shivashankar, G.; Kozlov, M.M. Model of T-cell nuclear deformation by the cortical actin layer. Biophys. J. 2013, 105, 1316-1323. [CrossRef]

133. Thomas, D.G.; Yenepalli, A.; Denais, C.M.; Rape, A.; Beach, J.R.; Wang, Y.-l.; Schiemann, W.P.; Baskaran, H.; Lammerding, J.; Egelhoff, T.T. Non-muscle myosin IIB is critical for nuclear translocation during 3D invasion. J. Cell Biol. 2015, 210, 583-594. [CrossRef]

134. Chen, M.B.; Whisler, J.A.; Jeon, J.S.; Kamm, R.D. Mechanisms of tumor cell extravasation in an in vitro microvascular network platform. Integr. Biol. 2013, 5, 1262-1271. [CrossRef]

135. Shenoy, V.B.; Wang, H.; Wang, X. A chemo-mechanical free-energy-based approach to model durotaxis and extracellular stiffness-dependent contraction and polarization of cells. Interface Focus 2016, 6, 20150067. [CrossRef]

136. Dahl, K.N.; Kahn, S.M.; Wilson, K.L.; Discher, D.E. The nuclear envelope lamina network has elasticity and a compressibility limit suggestive of a molecular shock absorber. J. Cell Sci. 2004, 117, 4779-4786. [CrossRef]

137. Liu, H.; Wen, J.; Xiao, Y.; Liu, J.; Hopyan, S.; Radisic, M.; Simmons, C.A.; Sun, Y. In situ mechanical characterization of the cell nucleus by atomic force microscopy. ACS Nano 2014, 8, 3821-3828. [CrossRef] [PubMed]

138. Funkhouser, C.M.; Sknepnek, R.; Shimi, T.; Goldman, A.E.; Goldman, R.D.; De La Cruz, M.O. Mechanical model of blebbing in nuclear lamin meshworks. Proc. Natl. Acad. Sci. USA 2013, 110, 3248-3253. [CrossRef] [PubMed]

139. Wren, N.S.; Zhong, Z.; Schwartz, R.S.; Dahl, K.N. Modeling nuclear blebs in a nucleoskeleton of independent filament networks. Cell. Mol. Bioeng. 2012, 5, 73-81. [CrossRef] [PubMed] 
140. Balakrishnan, S.; Mathad, S.S.; Sharma, G.; Raju, S.R.; Reddy, U.B.; Das, S.; Ananthasuresh, G. A Nondimensional Model Reveals Alterations in Nuclear Mechanics upon Hepatitis C Virus Replication. Biophys. J. 2019, 116, 1328-1339. [CrossRef] [PubMed]

141. Lin, Y. A model of cell motility leading to biphasic dependence of transport speed on adhesive strength. J. Mech. Phys. Solids 2010, 58, 502-514. [CrossRef]

142. Keren, K.; Pincus, Z.; Allen, G.M.; Barnhart, E.L.; Marriott, G.; Mogilner, A.; Theriot, J.A. Mechanism of shape determination in motile cells. Nature 2008, 453, 475. [CrossRef]

143. Lin, Y. Mechanics model for actin-based motility. Phys. Rev. E 2009, 79, 021916. [CrossRef]

144. Atilgan, E.; Wirtz, D.; Sun, S.X. Mechanics and dynamics of actin-driven thin membrane protrusions. Biophys. J. 2006, 90, 65-76. [CrossRef]

145. Liu, A.P.; Richmond, D.L.; Maibaum, L.; Pronk, S.; Geissler, P.L.; Fletcher, D.A. Membrane-induced bundling of actin filaments. Nat. Phys. 2008, 4, 789-793. [CrossRef] [PubMed]

146. Yang, L.; Gong, Z.; Lin, Y.; Chinthapenta, V.; Li, Q.; Webster, T.J.; Sheldon, B.W. Disordered topography mediates filopodial extension and morphology of cells on stiff materials. Adv. Funct. Mater. 2017, 27, 1702689. [CrossRef]

147. Wei, X.; Zhu, Q.; Qian, J.; Lin, Y.; Shenoy, V.B. Response of biopolymer networks governed by the physical properties of cross-linking molecules. Soft Matter 2016, 12, 2537-2541. [CrossRef]

148. Broedersz, C.P.; MacKintosh, F.C. Modeling semiflexible polymer networks. Rev. Mod. Phys. 2014, 86, 995. [CrossRef]

149. Lin, Y.; Wei, X.; Qian, J.; Sze, K.Y.; Shenoy, V.B. A combined finite element-Langevin dynamics (FEM-LD) approach for analyzing the mechanical response of bio-polymer networks. J. Mech. Phys. Solids 2014, 62, 2-18. [CrossRef]

150. Huang, H.; Tosun, A.B.; Guo, J.; Chen, C.; Wang, W.; Ozolek, J.A.; Rohde, G.K. Cancer diagnosis by nuclear morphometry using spatial information. Pattern Recognit. Lett. 2014, 42, 115-121. [CrossRef] [PubMed]

151. Gann, P.H.; Deaton, R.; Amatya, A.; Mohnani, M.; Rueter, E.E.; Yang, Y.; Ananthanarayanan, V. Development of a nuclear morphometric signature for prostate cancer risk in negative biopsies. PLoS ONE 2013, 8, e69457. [CrossRef] 